\title{
Electronic Structure Studies and Photocatalytic Properties of Cubic $\mathrm{Bi}_{1.5} \mathrm{ZnNb}_{1.5} \mathrm{O}_{7}$
}

\author{
Ganchimeg Perenlei, ${ }^{1}$ Jose A. Alarco, ${ }^{1,2}$ Peter C. Talbot, ${ }^{1,2}$ and Wayde N. Martens ${ }^{1}$ \\ ${ }^{1}$ Chemistry, Physics and Mechanical Engineering School, Science and Engineering Faculty, Queensland University of Technology, \\ Brisbane, QLD 4001, Australia \\ ${ }^{2}$ Institute for Future Environments, Science and Engineering Faculty, Queensland University of Technology, Brisbane, \\ QLD 4001, Australia
}

Correspondence should be addressed to Wayde N. Martens; w.martens@qut.edu.au

Received 20 May 2015; Revised 9 July 2015; Accepted 22 July 2015

Academic Editor: Ying Dai

Copyright (C) 2015 Ganchimeg Perenlei et al. This is an open access article distributed under the Creative Commons Attribution License, which permits unrestricted use, distribution, and reproduction in any medium, provided the original work is properly cited.

\begin{abstract}
The photocatalytic ability of cubic $\mathrm{Bi}_{1.5} \mathrm{ZnNb}_{1.5} \mathrm{O}_{7}(\mathrm{BZN})$ pyrochlore for the decolorization of an acid orange 7 (AO7) azo dye in aqueous solution under ultraviolet (UV) irradiation has been investigated for the first time. BZN catalyst powders prepared using low temperature sol-gel and higher temperature solid-state methods have been evaluated and their reaction rates have been compared. The experimental band gap energy has been estimated from the optical absorption edge and has been used as reference for theoretical calculations. The electronic band structure of BZN has been investigated using first-principles density functional theory (DFT) calculations for random, completely and partially ordered solid solutions of Zn cations in both the $A$ and $B$ sites of the pyrochlore structure. The nature of the orbitals in the valence band (VB) and the conduction band (CB) has been identified and the theoretical band gap energy has been discussed in terms of the DFT model approximations.
\end{abstract}

\section{Introduction}

The textile industry is one of the biggest consumers of synthetic dyes which comprise a large number of chemicals, mostly organic compounds [1]. Synthetic dyes can be classified into several groups based on their chromophoric groups in the structure. Azo dyes, commonly used as colourants, consist of one or more azo $(-\mathrm{N}=\mathrm{N}-)$ bonds coupling with several aromatic groups in the structure and account for $60-70 \%$ of all dyestuffs in the textile industry [2]. High concentration of dye residues in textile effluents has become a major source of water pollution. Treatment of dye wastewater is challenging, because it contains not only dyestuffs residues, but also various additives such as acidic and alkaline contaminants, pigments, heavy metals, and other organic pollutants [3]. Related research has recently focused on removing dyes from dye-containing effluents or decolorizing them through liquid fermentation [4].
Wastewater treatment through heterogeneous photocatalysis using semiconductor materials has received enormous attention as a cutting edge, energy efficient technology since the last decade. The main reason is that photocatalysis by itself, or in combination with other water treatment technologies, can provide simultaneous decomposition of a wide range of pollutants at a low energy cost [5]. A variety of semiconductor materials with increasing degree of complexity in composition have been investigated for the photocatalytic degradation of organic pollutants in aqueous media. Bi-based multimetal oxides, such as $\mathrm{BiMO}_{4}(\mathrm{M}=\mathrm{V}, \mathrm{Nb}, \mathrm{Ta})$ [6-8], $\mathrm{Bi}_{2} \mathrm{MO}_{6}(\mathrm{M}=\mathrm{Mo}, \mathrm{W})[9,10], \mathrm{BiOX}(\mathrm{X}=\mathrm{Cl}, \mathrm{Br}, \mathrm{I})[11]$, and $\mathrm{Bi}_{2} \mathrm{Ti}_{2} \mathrm{O}_{7}$ [12], have been considered as promising catalysts.

Photocatalysts containing mixed atoms or solid solutions in the crystal structure have also shown significant improvements in photocatalytic activity as compared with that of their simpler oxide end members; for example, $\mathrm{BiNb}_{x} \mathrm{Ta}_{1-x} \mathrm{O}_{4}$ and $\mathrm{Bi}_{2} \mathrm{Mo}_{x} \mathrm{~W}_{1-x} \mathrm{O}_{6}$ photocatalysts $(0 \leq x \leq 1)$ have performed 
better than $\mathrm{BiNbO}_{4} / \mathrm{BiTaO}_{4}$ [13] and $\mathrm{Bi}_{2} \mathrm{MoO}_{6} / \mathrm{Bi}_{2} \mathrm{WoO}_{6}$ [14], respectively. Another type of materials with mixed atoms, such as $\mathrm{Bi}_{2} \mathrm{MNbO}_{7}(\mathrm{M}=\mathrm{Al}, \mathrm{Ga}, \mathrm{In}, \mathrm{Fe})[15,16]$ and $\mathrm{Bi}_{2} \mathrm{MTaO}_{7}(\mathrm{M}=\mathrm{Al}, \mathrm{Ga}, \mathrm{In}, \mathrm{Fe})[17,18]$, has also been studied for photocatalytic removal of organic dye pollutants from water. These compounds have ideal pyrochlore structure with $A_{2} B_{2} \mathrm{O}_{7}$ general composition and generally exhibit diverse physical properties, which are useful for a wide range of applications $[19,20]$. These examples contain $p$-block $\mathrm{M}^{3+}$ metals (except for $\mathrm{Fe}$ ) along with $\mathrm{NbO}_{4}$ or $\mathrm{TaO}_{4}$ networks. Many of the aforementioned investigations have been experimentally driven and have not been matched with a corresponding level of complexity in electronic band structure calculations.

Recently, another set of $\mathrm{Bi}_{2} \mathrm{O}_{3}$-based complex pyrochlore compounds containing $\mathrm{M}^{2+}$ metals, such as $\mathrm{Bi}_{1.5} \mathrm{ZnTa}_{1.5} \mathrm{O}_{7}$ [21], $\mathrm{Bi}_{1.5} \mathrm{ZnSb}_{1.5} \mathrm{O}_{7}$ (BZS) [22], and $\mathrm{Bi}_{1.5} \mathrm{MNb}_{1.5} \mathrm{O}_{7}(\mathrm{M}=\mathrm{Zn}$, $\mathrm{Cu}, \mathrm{Ni}, \mathrm{Mn}, \mathrm{Mg}$ ) [23, 24], have received enormous attention for various nonphotocatalytic applications. Cubic $\mathrm{Bi}_{1.5} \mathrm{ZnNb}_{1.5} \mathrm{O}_{7}(\mathrm{BZN})$ with space group symmetry of $\mathrm{Fd}-3 \mathrm{~m}$ (number 227) is one of these ideal pyrochlore structures that may enable a wider range of metal substitutions targeted to specific properties of interest [25-30]. The crystal structure of cubic BZN is one of the most widely investigated structures throughout the literature using $\mathrm{X}$-ray and neutron diffraction techniques [31-33]; therefore, it can be considered as a good reference for additional research investigations. The $\mathrm{BZN}$ structure can be described in general as $A_{2} \mathrm{O}^{\prime} \cdot \mathrm{B}_{2} \mathrm{O}_{6}$ and specifically as $\left(\mathrm{Bi}_{1.5} \mathrm{Zn}_{0.5}\right)\left(\mathrm{Nb}_{1.5} \mathrm{Zn}_{0.5}\right) \mathrm{O}_{7}$ [34]. The $A$ site mainly contains $\mathrm{Bi}$ cations, while the $B$ site contains $\mathrm{Nb}$ cations. It is believed that $\mathrm{Zn}$ cations are equally divided between the two sites, with up to $25 \%$ of the $\mathrm{Bi}$ and $\mathrm{Nb}$ cations each being randomly substituted by $\mathrm{Zn}$, respectively $[32,35]$; however, there are some controversies about the percentage of Zn occupancy in the $A$ site. Both experimental and theoretical studies have focused on finding the optimal $A / B$ combinations for particular applications [32, 33]. Nevertheless, the need for a clearer correlation between the crystallographic structure and DFT calculated electronic band structures for this type of compounds is extant.

In this work, the photocatalytic ability of the cubic BZN compound has been investigated for the degradation of an azo dye solution for the first time. To further understand the photocatalytic properties of the material, the optical properties have been characterized by light absorption edge measurements and the effect of $\mathrm{Zn} 3 d$-orbitals on the electronic band structure has been systematically investigated by DFT calculations. Particular focus has been paid on the assumptions concerning the substitutions and the effects of these on the size and nature of the band gaps.

\section{Experimental Procedure}

2.1. Material Preparation. A commercial dye, acid orange 7 (AO7), has been selected as a representative of organic azo dye pollutants and has been purchased from Aldrich (Australia). An aqueous solution of AO7 with concentration of $20 \mathrm{mg} \mathrm{L}^{-1}$ has been prepared for the photocatalytic dye decolorization reactions. The BZN compounds used as the catalyst in the experiments have been prepared by two different methods, a conventional solid-state reaction and a sol-gel technique. The synthesis of the cubic BZN powders at various temperatures by the sol-gel method has been described in detail in a previous report [36]. In the case of the solid-state method, the BZN powders have been prepared from high purity $(99.9 \%)$ bismuth oxide $\left(\mathrm{Bi}_{2} \mathrm{O}_{3}\right)$, niobium oxide $\left(\mathrm{Nb}_{2} \mathrm{O}_{5}\right)$, and zinc oxide $(\mathrm{ZnO})$, which have also been purchased from Aldrich (Australia). The solid-state synthesis includes repeated mixing and heating processes, and the final product has been obtained at $1000^{\circ} \mathrm{C}$ after heating for $5 \mathrm{~h}$ in air.

2.2. Material Characterization. The crystal structures of the BZN powders have been analyzed by X-ray diffraction (XRD) using a Philips PANalytical X'Pert PRO X-Ray Diffractometer for phase identification. Surface morphologies of the compounds have been analyzed using a JEOL 7100F scanning electron microscope (SEM) coupled with energy-dispersive $\mathrm{X}$-ray spectroscopy (EDS). The samples have been coated with gold particles before the analysis to avoid charging at $20 \mathrm{kV}$. Specific surface areas of the powders have been measured by $\mathrm{N}_{2}$ adsorption/desorption isotherms by the Brunauer-Emmett-Teller (BET) method using a Micromeritics TriStar II 3020.

Optical analysis has been carried out to estimate the experimental band gaps of the BZN materials from absorption edges of UV-Vis diffuse reflectance spectra using a UV-Vis-NIR Cary 5000 Stheno spectrometer. The spectra have been recorded in the region of $200-800 \mathrm{~nm}$ wavelengths. These measurements have been complemented by mid-infrared (mid-IR) spectroscopy using the Perkin-Elmer 1600 series Fourier transform infrared spectroscopy (FTIR). The IR spectra have been recorded in the region of $650-$ $4000 \mathrm{~cm}^{-1}$ wavenumber.

2.3. Photocatalysis. The photocatalytic ability of the BZN materials has been evaluated by the decolorization of an $\mathrm{AO} 7$ solution under UV irradiation. The AO7 degradation process has been monitored by recording its maximum absorption peak $\left(\lambda_{\max }\right)$ at a wavelength of ca. $485 \mathrm{~nm}$, in the visible light region. The light source used in this experiment is a $15 \mathrm{~W}$ NEC blacklight FL15BL (ca. $365 \mathrm{~nm}$ wavelength). The photocatalytic reaction has been performed by adding $0.1 \mathrm{~g}$ of $\mathrm{BZN}$ powders to $10 \mathrm{~mL}$ of $\mathrm{AO} 7$ solution in a $30 \mathrm{~mL}$ glass vessel, which is then irradiated with UV light. The suspension has been stirred in the dark for 10 min using a magnetic stirrer, before switching on the UV light to start the reaction. After each experiment, the concentration of the dye solution has been determined by measuring its light absorption using a UV-Vis Cary 50 spectrometer.

\section{Theoretical Calculations}

3.1. Electronic Structure Calculations. The energy band structure and density of states (DOSs) of BZN have been calculated using density functional theory (DFT), as implemented in the Cambridge Serial Total Energy Package (CASTEP) of Materials Studio 8.0. All structures have been geometry 


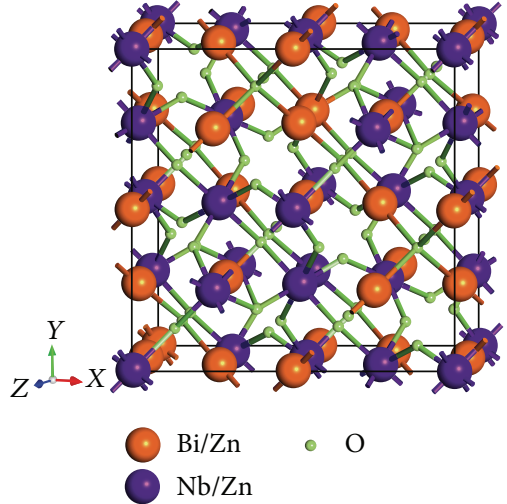

(a)

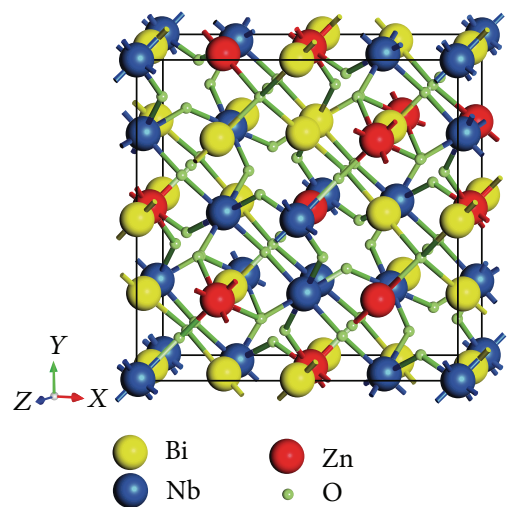

(b)

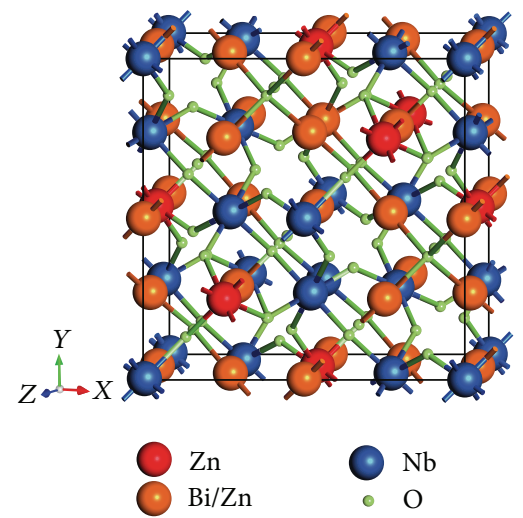

(c)

FIGURE 1: BZN structures viewed along the $\langle 100\rangle$ direction, assuming (a) random, (b) ordered, and (c) partially ordered solid solutions. Bi, $\mathrm{Nb}, \mathrm{Zn}$, and $\mathrm{O}$ atoms are yellow, blue, red, and green balls, respectively. Rules for color mixing are used to represent sites with fractional occupancy; therefore, $\mathrm{Bi} / \mathrm{Zn}$ and $\mathrm{Nb} / \mathrm{Zn}$ sites become orange (yellow + red) and purple (blue + red), respectively.

optimized first. Various calculation setups have been investigated using functionals for the Local Density Approximation (LDA) or the Generalized Gradient Approximation (GGA), cut-off energy values from 300 to $1000 \mathrm{eV}$, k-grids from 0.03 to $0.07 \mathrm{~A}^{-1}$, and metal and nonmetal choices. A range of convergence tolerances including ultrafine and fine setups and various assumptions on spin polarization in the calculations have also been investigated, particularly when the standard setup has resulted in difficulty achieving convergence and when the converged results have indicated that no band gap is present. However, in most typical calculations, the GGA with Perdew-Burke-Ernzerhof (PBE) functional with normconserving pseudopotentials has been adopted along with kgrid of $0.03 \mathrm{~A}^{-1}$ giving a $6 \times 6 \times 6 \mathrm{k}$-point mesh, plane wave basis set cut-off of $830 \mathrm{eV}, 100$ empty orbitals, and nonmetal, nonspin, and ultrafine convergence tolerance setups.

3.2. $\mathrm{Bi}_{1.5} \mathrm{ZnNb} b_{1.5} \mathrm{O}_{7}$ Structure. The crystal structures of BZN used in DFT calculations have been taken and/or adapted from Crystallographic Information File (CIF) from the Inorganic Crystal Structure Database (ICSD). The starting cubic BZN structure (JCPDS PDF, 04-016-3002) has lattice parameter $a=10.56(\AA)$ and contains fractionally occupied cations at the $\mathrm{Bi}(A)$ and $\mathrm{Nb}(B)$ sites with ratios of $\mathrm{Bi} / \mathrm{Zn}=$ $78.125: 21.875$ and $\mathrm{Nb} / \mathrm{Zn}=75: 25$, respectively [32]. With fractional occupancy, the structure represents a random solid solution as illustrated in Figure 1(a). Atoms are displayed using a ball and stick style and rules for color mixing are used to represent sites with fractional occupancy. Mixed cations of $\mathrm{Bi} / \mathrm{Zn}$ and $\mathrm{Nb} / \mathrm{Zn}$ are therefore orange (yellow + red) and purple (blue + red) balls, respectively, and pure $\mathrm{O}$ anions are green balls.

Another approach for $\mathrm{Zn}$ cation substitution at specific sites of the BZN structure has also been investigated by DFT calculations. In this case, the fractional occupancy is removed and a quarter (25\%) of $\mathrm{Bi}$ and a quarter $(25 \%)$ of $\mathrm{Nb}$ cations at specific sites are replaced by $\mathrm{Zn}$ cations. This approach incorporates new periodicities for the $\mathrm{Zn}$ substitutions and can be considered as an ordered solid solution. It is an approach that has previously been used in the literature to investigate the stability of potential specific substitutions by looking at the enthalpy [34, 37]; however, no report has been made of the effects of these site substitution choices on the electronic band structure and/or the band gaps. There is a large variety of possible choices for substituted Zn cations. The four main different substitution arrangements discussed in the above mentioned stability study [37] have been investigated in our work. An example structure, which has shown the most representative and consistent results with experiments, is displayed in Figure 1(b). Pure Bi and pure $\mathrm{Nb}$ are now yellow and blue, respectively, while substituted $\mathrm{Zn}$ atoms are red balls.

BZN structures containing a combination of both random and ordered $\mathrm{Zn}$ cations substitutions have also been investigated using DFT calculations and are referred to as partially ordered solid solutions. In these cases, the $\mathrm{Zn}$ substitution at either the $A$ or the $B$ sites is randomly substituted while the other is ordered or vice versa. Figure 1(c) shows the partially ordered BZN structure, where Zn cation substitutions are random at the $A$ site, whereas ordered at the $B$ site, respectively. As described above mixed cations of $\mathrm{Bi} / \mathrm{Zn}$ are orange, pure $\mathrm{Nb}$ cations are blue, pure $\mathrm{O}$ anions are green, and substituted $\mathrm{Zn}$ cations at the $B$ site are red balls, respectively.

\section{Results and Discussion}

4.1. Phase Identification. The XRD patterns of the BZN powders synthesized at 550 and $1000^{\circ} \mathrm{C}$ by the sol-gel and the solid-state techniques, respectively, are shown in Figure 2. The main crystal peaks in the patterns are indexed to $\mathrm{Bi}_{1.5} \mathrm{ZnNb}_{1.5} \mathrm{O}_{7}$ (JCPDS PDF, 04-016-3002) in the ICSD database, which indicates that the cubic BZN compounds are obtained at both sintering temperatures. The reduced crystal peak widths for materials prepared with increased sintering temperature confirm an increasing degree of crystallinity as determined using the Scherrer equation. 


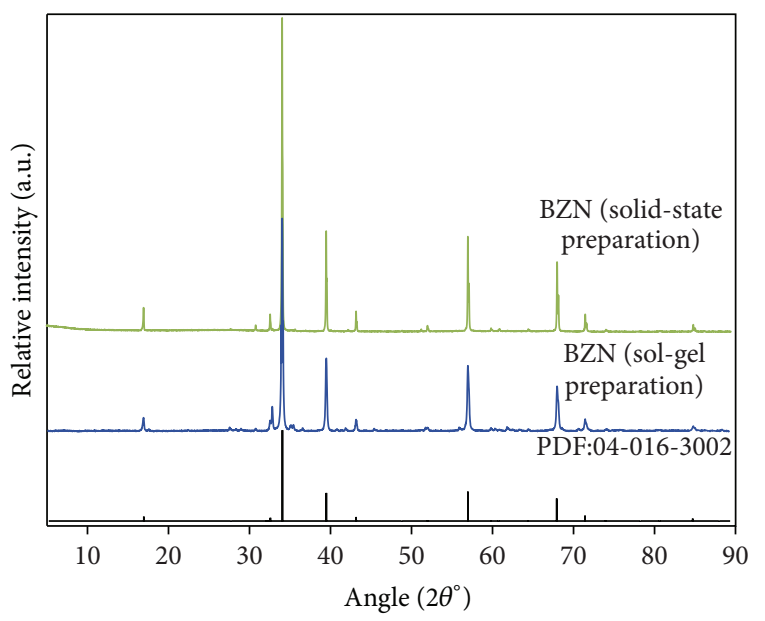

FIGURE 2: XRD patterns of the BZN powders prepared at $550^{\circ} \mathrm{C}$ by the sol-gel and at $1000^{\circ} \mathrm{C}$ by the solid-state methods (the bottom pattern is the PDF card number for the cubic BZN).

TABLE 1: Surface area and dye decomposition dependence on the heating temperature of the BZN catalyst (as percentage), after $1 \mathrm{~h}$ of photocatalytic reaction.

\begin{tabular}{lccc}
\hline $\begin{array}{l}\text { Temperature } \\
\left({ }^{\circ} \mathrm{C}\right)\end{array}$ & $\begin{array}{c}\text { Grain size } \\
(\mu \mathrm{m})\end{array}$ & $\begin{array}{c}\text { Surface area } \\
\left(\mathrm{m}^{2} \mathrm{~g}^{-1}\right)\end{array}$ & $\begin{array}{c}\text { Dye } \\
\text { decomposition } \\
\text { percentage }(\%)\end{array}$ \\
\hline 500 & $\begin{array}{c}\text { Less than } \\
0.5\end{array}$ & 25.28 & 79.30 \\
550 & About 0.5 & 14.41 & 77.67 \\
600 & $0.7-0.8$ & 11.89 & 66.97 \\
700 & Less than 1 & 2.29 & 34.51 \\
800 & About 1 & 0.36 & 20.22 \\
900 & Above 1 & 0.34 & 14.15 \\
1000 & $1-3$ & 0.30 & 14.00 \\
\hline
\end{tabular}

4.2. Surface Morphology. The SEM micrographs of the BZN powders prepared at 550 and $1000^{\circ} \mathrm{C}$ by the sol-gel and solidstate reaction methods, respectively, are shown in Figure 3. The surface morphology of the powders suggests that the low temperature sol-gel method provides relatively fine and uniform microstructure with grain size of about $0.5 \mu \mathrm{m}$ as seen in Figure 3(a).

Conversely, the SEM microstructure in Figure 3(b) shows less homogeneous particles with grain sizes varying from about $1 \mu \mathrm{m}$ to above. A small amount of Bi-rich particles by EDS analysis is also observed on the grain boundaries of materials prepared by the solid-state method. This is likely an indication of formation of the residual impurities or of incomplete homogeneity achieved by mechanical mixing of the different metal oxides. Measured BET surface areas have been consistent with the grain size determinations and are listed in Table 1.

4.3. Optical Absorption Analysis. The optical absorption curves of the BZN powders prepared by the two different methods are displayed in Figure 4. Although the grain sizes vary with the processing temperature, their optical band gaps appear very similar. The band gap values estimated from the UV-Vis spectra are about 2.75 and $2.90 \mathrm{eV}$ at 550 and $1000^{\circ} \mathrm{C}$, respectively.

The optical measurement of the BZN powders has also been extended to higher wavelength regions using mid-IR spectroscopy to examine possible lower energy absorption features. A possible small absorption edge could be seen at $900-1300 \mathrm{~cm}^{-1}(0.11-0.16 \mathrm{eV})$; however, it is not very conclusive whether this is the result of electronic transitions within levels in the band structure or not. The experimental band gap values suggest that the BZN powders may have an ability to utilize energy wavelengths of ca. $430 \mathrm{~nm}$ and below, that is, that the compound might be responsive to UV irradiation.

4.4. Photocatalytic Dye Decolorization. The changes in the concentration of the $\mathrm{AO} 7$ dye solution under UV irradiation for $120 \mathrm{~min}$ in the presence and absence of catalysts are shown in Figure 5. It is apparent from the time-dependent graphs of the dye degradation that no clear sign of dye degradation has been observed in the absence of any catalyst under UV irradiation. However, a slight decrease of concentration of the dye solution (3-4\%) has been observed after $120 \mathrm{~min}$ of experiment duration. This decrease is due to the slow photolysis of this catalyst under these conditions and represents a baseline for no catalyst.

In the presence of the BZN powders, the degradation of the dye solution is noticeably increased under UV irradiation; however, the photocatalytic activity of the BZN samples varies depending on the catalyst preparation methods. When the BZN catalyst prepared by the solid-state method at $1000^{\circ} \mathrm{C}$ is used in the reaction, the observed decolorization of the dye solution is considerably lower than that of the sol-gel BZN catalyst. Only about $18 \%$ of the dye solution has been degraded in the $120 \mathrm{~min}$ of experiment duration. This might be due to the larger particle size/smaller surface area of the powders synthesized at relative high temperature or the presence of phase impurities in the material interfering with the performance. Although this method is less recommended for the preparation of homogeneous catalyst materials, it is still informative to examine it for comparison, as this is the most commonly employed synthetic method for the preparation of cubic BZN in the literature.

On the other hand, the low temperature $\left(550^{\circ} \mathrm{C}\right) \mathrm{BZN}$ catalyst prepared by the sol-gel method has shown significant activity for the photodegradation of the dye solution under UV irradiation. In fact, more than $50 \%$ of the dye concentration has been reduced within the first $30 \mathrm{~min}$, further decolorization of approximately $95-96 \%$ of the dye has been reached within $120 \mathrm{~min}$, and, shortly after, complete removal is achieved. This result indicates that the BZN compound is photoactive under UV light with wavelength of ca. $365 \mathrm{~nm}$. Therefore, the faster photocatalytic degradation of the azo dye in aqueous media is achieved with assistance of the BZN catalyst photoexcited by UV irradiation.

Figure 6 shows the kinetics of the photocatalytic decolorization of the $\mathrm{AO} 7$ dye solution in the presence of the $\mathrm{BZN}$ catalysts on a logarithmic scale. The plots of dye concentration versus experimental duration show that the reaction rates 


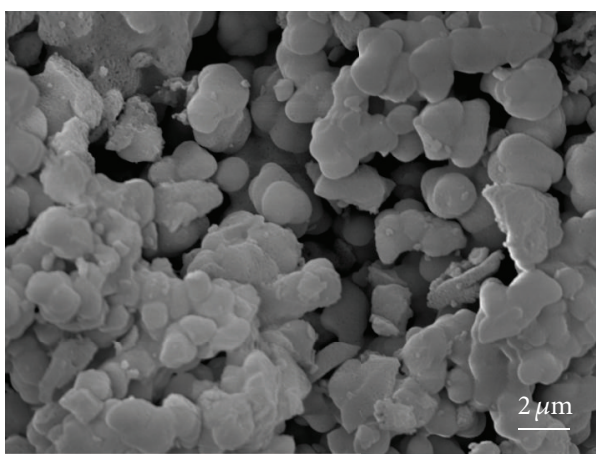

(a)

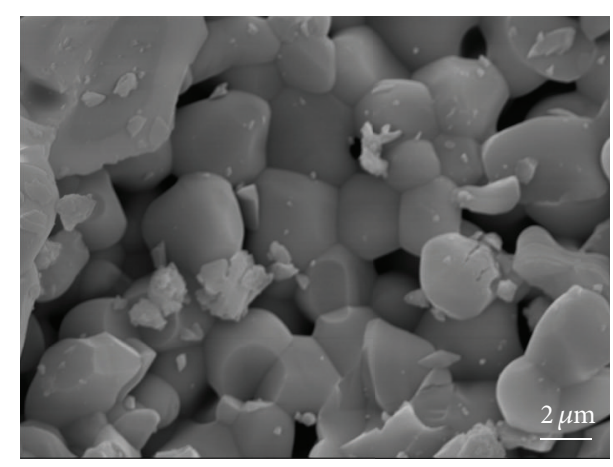

(b)

FIGURE 3: Surface morphology of the BZN prepared at (a) $550^{\circ} \mathrm{C}$ by the sol-gel and (b) $1000^{\circ} \mathrm{C}$ by the solid-state methods.

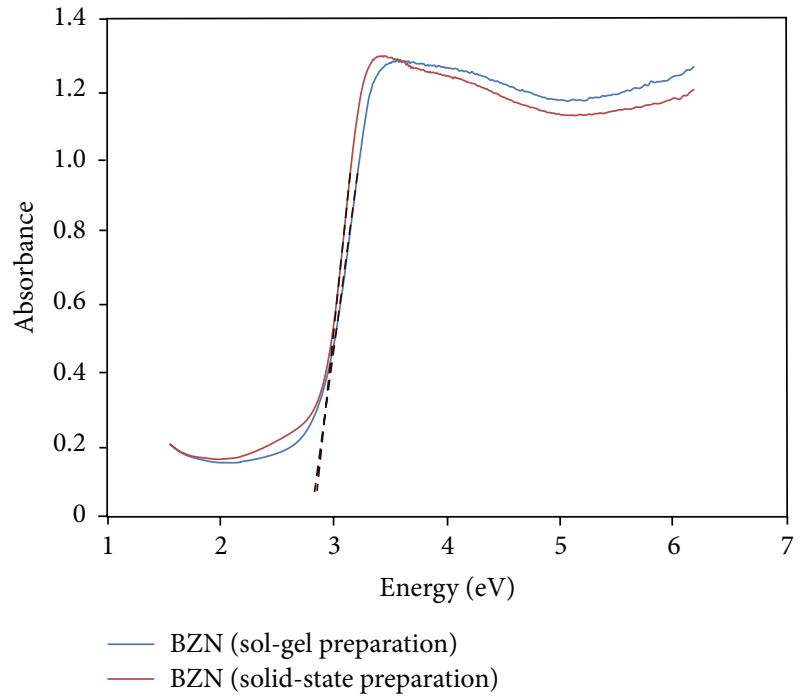

FIgURE 4: Absorption edge of the BZN powders prepared at $550^{\circ} \mathrm{C}$ by the sol-gel and $1000^{\circ} \mathrm{C}$ by the solid-state methods.

can be described by a pseudo-first-order kinetic model with formula, $\ln \left(C_{0} / C\right)=k t$, where $C_{0}$ is the initial concentration and $C$ is the concentration at time, $t$. The photocatalytic dye degradation rate using the BZN powders prepared by the solid-state method has shown considerably slower kinetics than that obtained using the BZN powders prepared by the sol-gel method. The calculated apparent rate constants are 0.024 and $0.002 \mathrm{~min}^{-1}$ for the powders prepared at $550^{\circ} \mathrm{C}$ by the sol-gel and at $1000^{\circ} \mathrm{C}$ by the solid-state methods, respectively. These different reaction rates suggest that the reaction rate is determined by a corresponding different number of active sites on the surface of the BZN powders for the different particle sizes and surface areas.

Additional experiments on the dye decolorization reaction have been carried out using the BZN catalyst synthesized at different temperatures to further examine the influence of processing temperature on the surface area and consequently the reaction rate. Catalyst powders prepared by the sol-gel method have been heated in air at various temperatures in

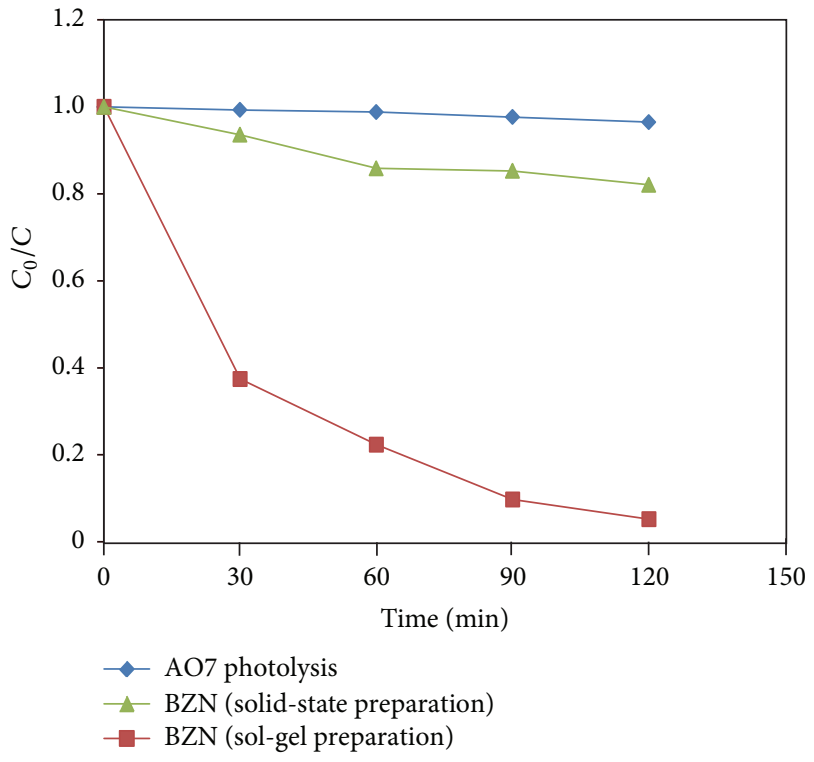

FIgURE 5: The changes in concentration of the AO7 dye solution under UV irradiation with and without the BZN catalysts.

the range $500-900^{\circ} \mathrm{C}$ for $5 \mathrm{~h}$, for this comparison. A new set of photocatalytic reactions, using the same initial concentration of dye solution and amount of catalyst, have been run under UV irradiation for $60 \mathrm{~min}$ with these powders. The surface areas of the BZN powders and the percentage of decomposed AO7 dye concentration detected at $\lambda_{\max }=485 \mathrm{~nm}$ after $1 \mathrm{~h}$ through the catalytic reaction are listed in Table 1 . It can be clearly seen from the table that the photocatalytic activity of the BZN powders is highest at the lowest sintering temperature of $500^{\circ} \mathrm{C}$ and that it constantly declines with increasing temperature.

This result is similar to a previous report in the literature, where $\mathrm{Bi}_{2} \mathrm{FeNbO}_{7}$ catalysts prepared at the lowest temperature of $400^{\circ} \mathrm{C}$ by sol-gel have shown much better performance than the higher temperature catalysts for methylene blue dye degradation [15]. Note that the surface area and the degraded concentrations of the dye using the BZN powders prepared at $1000^{\circ} \mathrm{C}$ by the solid-state method show similar results to 


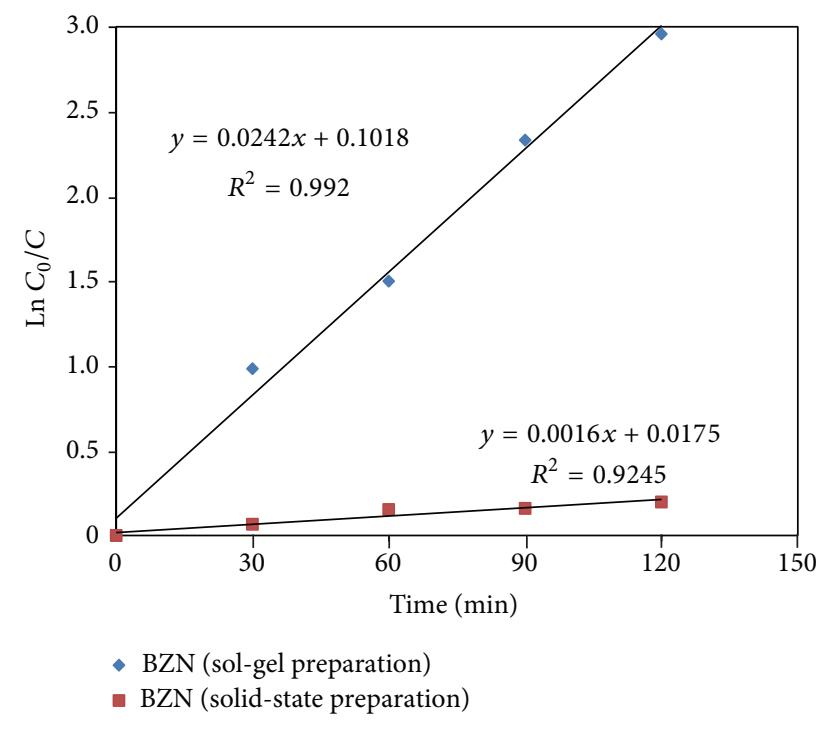

FIGURE 6: Reaction kinetics for the BZN catalysts prepared by different synthetic methods.

those obtained for the sol-gel prepared BZN powders heated to 800 and $900^{\circ} \mathrm{C}$.

Some other parameters that might affect the overall dye degradation reaction such as concentration of catalyst, initial concentration of dye solution, and usage of different lamp have also been briefly studied. It has been found that the photocatalytic reaction rate is influenced by both the catalyst dosage and the initial concentration of the dye solution. However, increasing the catalyst amount to speed up the dye removal process reaches a point where an excess amount of catalyst in the solution begins to block the efficient absorption of photons.

Moreover, the stability of the BZN catalysts has been examined by their repeated usage in photocatalytic dye degradation reactions under the same experimental conditions. For such tests, the BZN powders from an initial experiment have been centrifuged, cleaned, and dried before reapplying them in subsequent experiments. It has been determined that the BZN catalyst can be reused at least 3 times repeatedly for the photocatalytic reaction without changing its performance. The XRD patterns of the catalyst have also been collected after the reactions and found to be unchanged. Experiments in the dark have also shown that there is no change in the dye concentration, which is an indication of limited or no surface absorption onto the BZN catalyst.

4.5. Electronic Structure Calculation. As mentioned earlier, the electronic band structures and the DOSs for random, ordered, and partially ordered solid solutions have been investigated using DFT calculations. Among the ordered and partially ordered solid solutions, various combinations have been studied, but the specific arrangements shown in Figures 1(b) and 1(c) have been selected as providing the most representative results.
4.5.1. BZN Random Solid Solution. All attempts to calculate the electronic band structure of the BZN with fractional occupancy and no spin have resulted in metallic-like materials without band gaps near or from the Fermi level (see Figure $7(\mathrm{a})$ ). These results have been consistent for all different settings (k-grid, cut-off energy, etc.) used in the calculations when the calculation is spin unpolarized for both cubic and primitive BZN structures.

Since this has not reflected the experimentally observed optical results, spin polarized calculations have also been explored in the DFT studies. Figure 7(c) shows the energy band diagram obtained for the random solid solution of the cubic structure assuming spin is equal to 2 and using ultrafine convergence criteria (energy $=5.0 \times 10^{-6} \mathrm{eV}$ atoms $^{-1}$, force $=$ $0.01 \mathrm{eV}^{-1}$, stress $=0.02 \mathrm{GPa}$, and displacement $=5.0 \times$ $10^{-4} \AA$ ) with cut-off energy of $830 \mathrm{eV}$.

A band gap clearly develops slightly $(\sim 1 \mathrm{eV})$ above the Fermi level (defined at $0 \mathrm{eV}$ ); however, the states in the vicinity of the Fermi level appear to be localized impurity bands, above dense states in the VB $(\sim-1 \mathrm{eV})$, while a dense $\mathrm{CB}$ begins at about $2 \mathrm{eV}$, as can be seen in Figure 7(c). Direct band gaps of about 2.7 and $2.9 \mathrm{eV}$ between the dense $\mathrm{VB}$ and $\mathrm{CB}$ regions have been estimated for the alpha and beta spins, respectively, at the $G$ point in reciprocal space. The nature of the localized bands as impurity bands seems further confirmed by the fact that the calculation assigns the Fermi energy at $-0.95 \mathrm{eV}$ to the result, indicating that the middle point between a fully occupied continuous VB and the top of the localized impurity bands has been taken as the Fermi level. This suggests that some optical absorption may be seen between the continuous VB bands and the impurity bands but that the main optical absorption edge will take place between the continuous $\mathrm{VB}$ and the continuous excited $\mathrm{CB}$ which is separated by about $2.7-2.9 \mathrm{eV}$.

The DOS curves for BZN random solid solutions are shown in Figures 7(b) and 7(d). A relatively dense band around the Fermi level in the electronic band structure with unpolarized spins, which consists mainly of $d$ and $p$ states in Figure 7(b), becomes significantly less dense when spin polarization is applied in the calculations. Here, the presence of impurity bands observed in the electronic band structure in Figure $7(d)$ is nevertheless due to the presence of $\mathrm{Zn}$ cations in the structure, indirectly if not directly.

4.5.2. BZN Ordered Solid Solution. Since the random solid solution model has not given very good match to optical absorption results, apart from some spin polarized cases, the substitution of $\mathrm{Zn}$ cations at specific positions in the $A$ and $B$ sites of the BZN structure has also been investigated by DFT calculations with and without spin polarization. Similar to the studies of random solid solutions, calculations for ordered solid solution have also compared (or attempted to compare) primitive and symmetry options. For the spin polarized case, only primitive structures choices have resulted in completed calculations.

Calculations that have attempted to retain the structural symmetry have led to convergence difficulties, presumably 


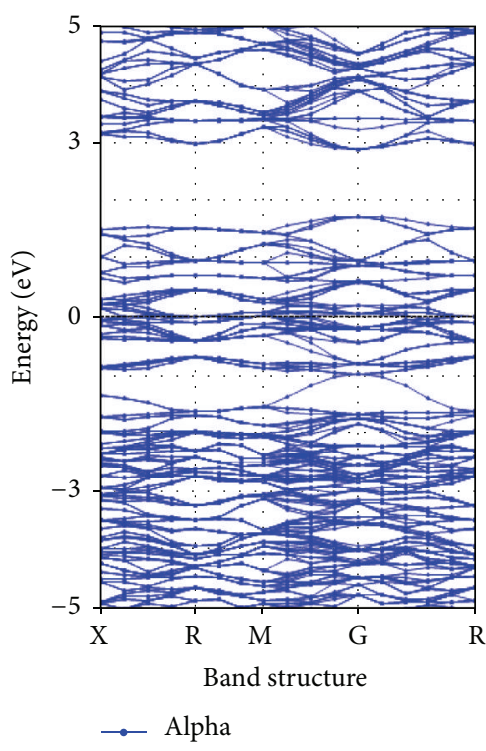

(a)

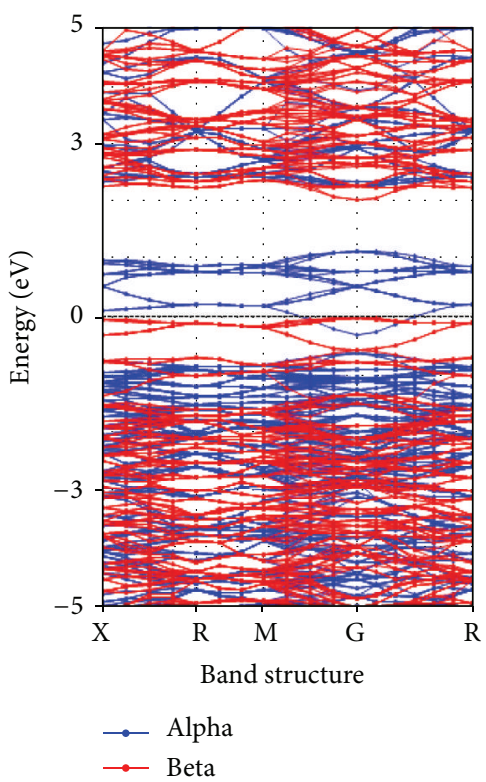

(c)

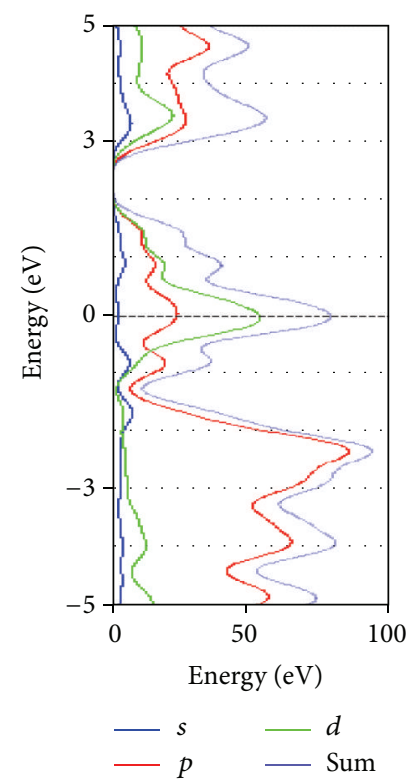

(b)

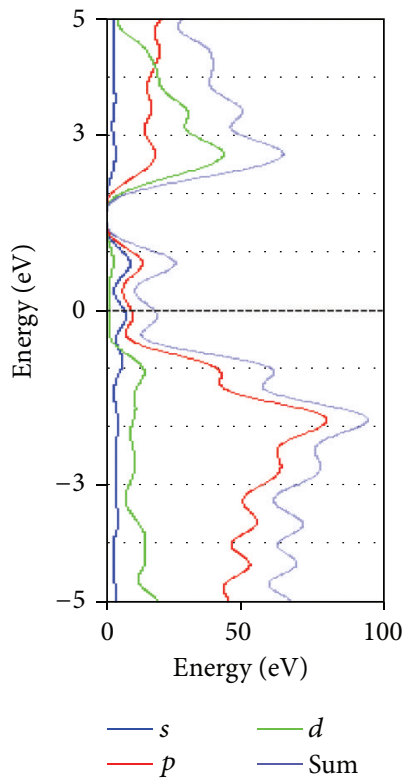

(d)

FIGURE 7: The band structures and DOSs for the cubic BZN random solid solution structure for ((a) and (b)) spin unpolarized and ((c) and (d)) spin polarized calculations.

due to the large number of atoms and complexity of the structure. The primitive choice typically ends up into a triclinic structure, while the symmetry choice forms an orthorhombic structure after their respective geometry optimizations. To achieve convergence, criteria have been customized to less demanding values than the usual default values (also, than those which have been used for random solid solutions). Final convergence has been generally obtained with customized tolerance setups using combinations for energy $=5.0 \times$ $10^{-5} \mathrm{eV}$ atoms $^{-1}$, force $=0.03 \mathrm{eV} \AA^{-1}$, stress $=0.02 \mathrm{GPa}$, and displacement $=5.0 \times 10^{-3} \AA$, respectively, with k-grid of
$0.07 \mathrm{~A}^{-1}$, which gives a k-point mesh of $2 \times 2 \times 2$ and cut-off energy of $750 \mathrm{eV}$.

Figure 8 shows the energy band diagram and DOS contributed by all the different atoms in the modified BZN ordered solid solution with C-centered orthorhombic structure. Note that there are also localized states between dense regions of $\mathrm{VB}$ and $\mathrm{CB}$ states. The energy band diagram shown in Figure 8(a) is the most representative result of the ordered solid solutions investigated with a spin unpolarized choice. The energy band structure of BZN ordered solid solution with a spin polarized choice is nearly identical to that of 


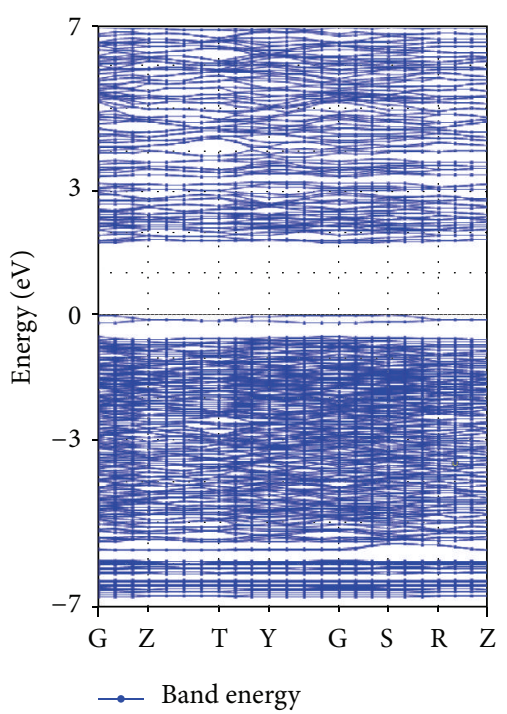

(a) Band structure

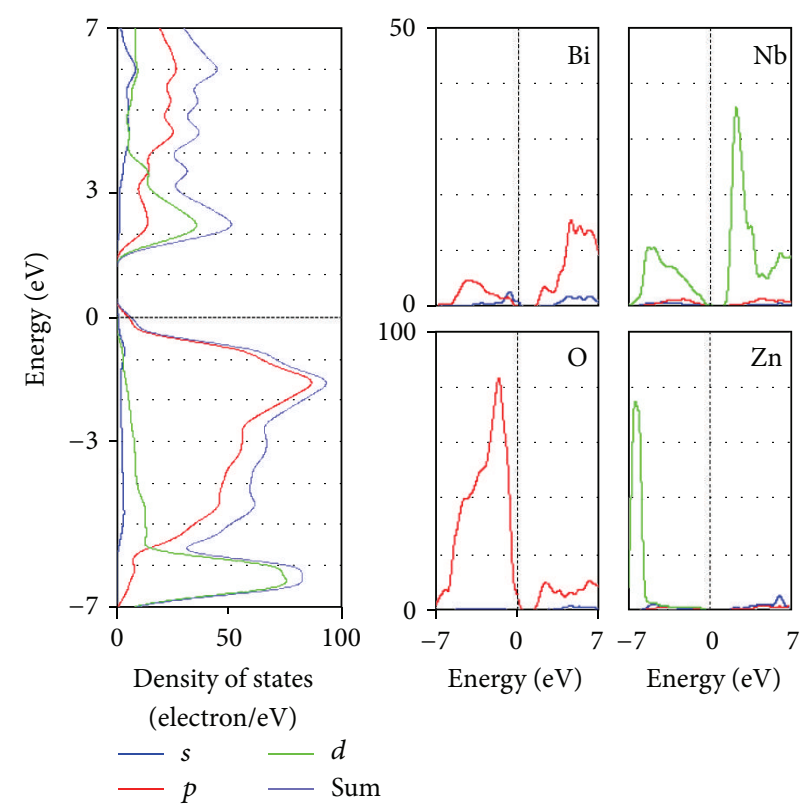

(b) Density of states

FIGURE 8: The band structure and DOS for the C-centered orthorhombic BZN ordered solid solution.

the spin unpolarized cases. It is also the most consistent with the experimental gap and the results obtained for the spin polarized choices for the BZN random solid solution, if we assume that the optical absorption is mainly due to transitions between the dense groups of states with a separation of about $2.25 \mathrm{eV}$ at the $\mathrm{G}$ point in reciprocal space.

Figure 8 (b) displays the total and partial DOS for the selected BZN ordered solid solution. The VB mainly consists of $\mathrm{O} 2 p$ states, whereas the $\mathrm{CB}$ consists mainly of $\mathrm{Nb} 4 d, \mathrm{O}$ $2 p$, and $\mathrm{Bi} 6 p$ states. A small amount of $\mathrm{Bi} 6 s$ states is also found on the top of $\mathrm{O} 2 p \mathrm{VB}$ states, which helps raise the level of VB slightly. With respect to the contribution of $\mathrm{Zn}$ to the electronic band structure, a pronounced peak of $3 d$ states is obtained between -5.5 and $-7.0 \mathrm{eV}$. This energy level is several eVs below the Fermi level and it may therefore only contribute indirectly to the determination of the size of the band gap.

4.5.3. BZN Partially Ordered Solid Solution. The partially ordered solid solution produced optimized results combining some of the desirable features of the separate random and ordered solid solution results, such as less distortion with retention of the orthorhombic and cubic structure after geometry optimization, ability to use more demanding convergence criteria, and presence of an electronic band gap, all of these simultaneously. Convergence has been reached using fine convergence criteria (energy $=1.0 \times 10^{-5} \mathrm{eV}$ atoms $^{-1}$, force $=0.03 \mathrm{eV} \AA^{-1}$, stress $=0.05 \mathrm{GPa}$, and displacement $=$ $1.0 \times 10^{-3} \AA$ ), respectively, with k-grid of $0.03 \mathrm{~A}^{-1}$, which gives a k-point mesh of $4 \times 4 \times 4$ and cut-off energy of $750 \mathrm{eV}$.

Figure 9 illustrates the energy band diagram and total and partial DOS for the BZN partially ordered solid solution, where the $A$ site is random, while the $B$ site is ordered. A band gap of about $2.2 \mathrm{eV}$ (between dense groups of states) has been obtained at the $G$ point in reciprocal space for the orthorhombic BZN structure, which is the same as the band gap obtained from the ordered BZN solid solution calculations; however, the localized levels have been shifted to slightly higher energy inside this gap. This result is still lower than the experimentally estimated band gap values of about 2.7-2.8 eV. A similar difference between calculated and experimental values has been determined for pure $\mathrm{BiNbO}_{4}$, where the calculated band gap is about $2.3 \mathrm{eV}$ for the orthorhombic structure, whereas the estimated experimental band gap for powders prepared by the sol-gel method is about $2.7 \mathrm{eV}$.

The localized impurity bands seem to arise from $\mathrm{Zn} s$ orbitals in the mixed $\mathrm{Bi} / \mathrm{Zn}$ cations positions of the random solid solution. Such impurity bands may act as traps for photogenerated electrons during the photocatalytic reaction. The energy band structure of BZN partially ordered solid solution with a spin polarized choice is nearly identical to that of the spin unpolarized cases.

Conversely, while retaining the cubic structure, when the $\mathrm{Zn}$ substitutions on the $A$ and the $B$ sites are ordered and random, respectively, no band gap appears which is similar to the calculated results from the random solid solution structure (unpolarized case). $\mathrm{Nb} d$ orbitals are driven downwards in energy by the involvement of $\mathrm{Zn}$ cations in the $B$ site of the BZN structure as $\mathrm{Nb} / \mathrm{Zn}$ mixed cations. This energy downshift of $\mathrm{Nb} d$ orbitals diminishes when spin polarization is introduced in the DFT calculations.

4.5.4. Summary of Calculated Results. Table 2 summarizes the DFT calculation results for BZN random, completely and partially ordered solid solutions. The obtained final enthalpy of formation of $-58427.17 \mathrm{eV}$ for the ordered BZN solid solution is generally lower than the enthalpy of formations 


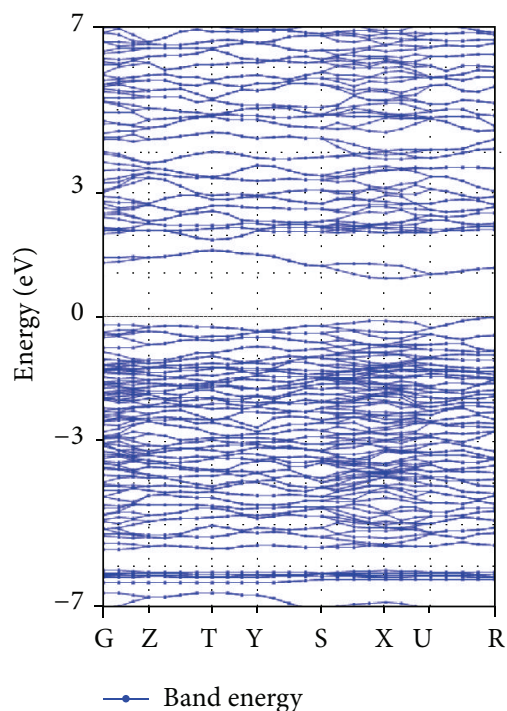

(a) Band structure

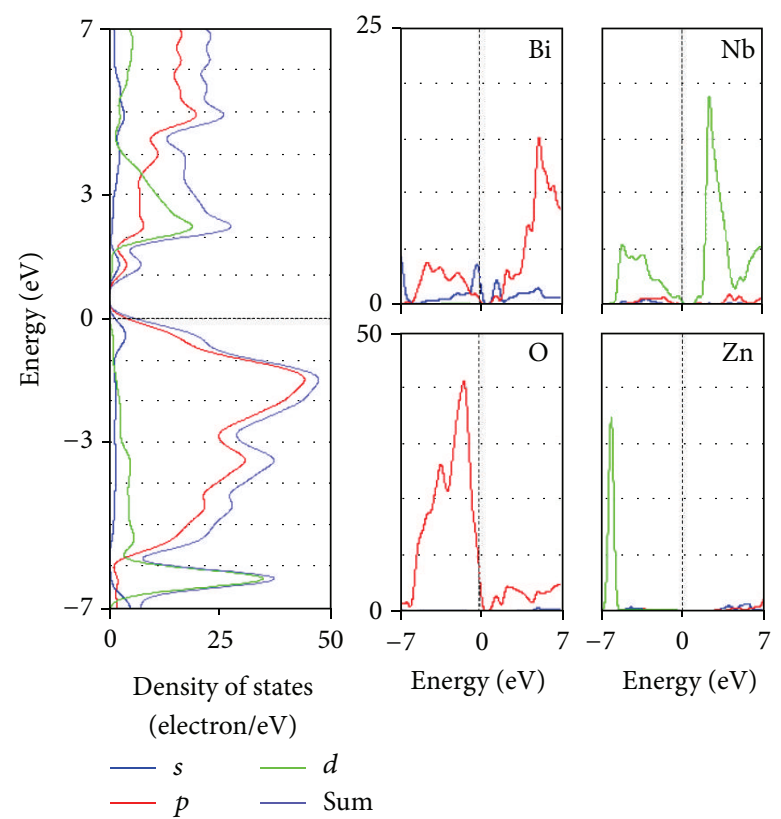

(b) Density of states

FIGURE 9: The band structure and DOS for the orthorhombic BZN partially ordered solid solution.

TABLE 2: Comparison of parameters obtained with DFT-GGA calculations for BZN random, ordered, and partially ordered solid solutions.

\begin{tabular}{|c|c|c|c|c|c|c|c|}
\hline $\begin{array}{l}\text { BZN solid } \\
\text { solution }^{\text {a }}\end{array}$ & $\begin{array}{l}\text { Calculated } \\
\text { symmetry }\end{array}$ & $\begin{array}{c}\text { Spin } \\
\text { polarization }\end{array}$ & $\begin{array}{c}\text { Lattice } \\
\text { length }(\AA)\end{array}$ & $\begin{array}{c}\text { Lattice } \\
\text { angles }\left({ }^{\circ}\right)\end{array}$ & $\begin{array}{c}\text { CASTEP } \\
\text { formation } \\
\text { energy }(\mathrm{eV})\end{array}$ & $\begin{array}{c}\text { CASTEP } \\
\text { normalized } \\
\text { energy } \\
(\mathrm{kJ} / \mathrm{mol})\end{array}$ & $\begin{array}{c}\text { Band gap } \\
(\mathrm{eV})\end{array}$ \\
\hline \multirow{4}{*}{ Random } & Cubic & No spin & 10.48 & 90 & -56362.37 & -156.56 & No gap \\
\hline & Cubic & Spin $=2$ & 10.44 & 90 & -56371.45 & -156.58 & $2.7 ; 2.9$ \\
\hline & Primitive $^{b}$ & No spin & 7.41 & 60 & -14090.59 & -156.56 & No gap \\
\hline & Primitive & Spin $=2$ & 7.41 & 60 & -14096.12 & -156.62 & 2.9 \\
\hline \multirow{3}{*}{ Ordered } & $\begin{array}{l}\text { C-centered } \\
\text { orthorhombic }\end{array}$ & No spin & $\begin{array}{l}10.86 \\
10.86 \\
10.71\end{array}$ & $\begin{array}{c}90 \\
90 \\
89.49\end{array}$ & -58427.17 & -162.29 & 2.2 \\
\hline & Triclinic & No spin & $\begin{array}{l}10.87 \\
10.74 \\
10.85\end{array}$ & $\begin{array}{l}90.03 \\
90.79 \\
89.93\end{array}$ & -58427.27 & -162.29 & 2.2 \\
\hline & Triclinic & Spin $=2$ & $\begin{array}{l}10.87 \\
10.74 \\
10.84 \\
\end{array}$ & $\begin{array}{l}89.99 \\
90.82 \\
90.00 \\
\end{array}$ & -58427.31 & -162.29 & 2.2 \\
\hline \multirow{2}{*}{$\begin{array}{l}\text { Partially } \\
\text { ordered } \\
\text { ( } B \text { site })\end{array}$} & Orthorhombic & No spin & $\begin{array}{c}7.61 \\
7.52 \\
10.82\end{array}$ & 90 & -29253.78 & -162.52 & 2.2 \\
\hline & Orthorhombic & Spin $=2$ & $\begin{array}{c}7.61 \\
7.52 \\
10.76\end{array}$ & 90 & -29253.79 & -162.52 & 2.2 \\
\hline $\begin{array}{l}\text { Partially } \\
\text { ordered } \\
(A \text { site })^{\mathrm{d}}\end{array}$ & Cubic & No spin & 10.58 & 90 & -56278.65 & -156.32 & No gap \\
\hline
\end{tabular}

${ }^{\mathrm{a}}$ The input structure is adapted from the cubic BZN cif $(a=10.56 \AA)$.

${ }^{\mathrm{b}}$ The input structure converted to primitive has lattice parameter $7.46 \AA$ with $60^{\circ}$ angles.

${ }^{c}$ The CASTEP program labels the result structure as C-centered orthorhombic even though there is a small deviation from $90^{\circ}$ in one of the angles.

${ }^{\mathrm{d}}$ Spin polarization in this case resulted in job failure during calculations. 
of $-56362.37 \mathrm{eV}$ for the random solid solution. Such a result is often taken as an indication of favourable formation; however, the final structure obtained is slightly distorted from the initial (experimental) cubic structure, as can be seen in Table 2.

Geometry optimization of the BZN random solid solution produces a contraction of the lattice parameters $(a=$ $10.48 \AA$ ), while the opposite takes place for the ordered solid solution ( $a=10.86 \AA$ ) as compared to the initial cubic structure ( $a=10.56 \AA$ ), when the GGA function is in use. In the case for the LDA function in the calculations, slight decreases in the lattice parameters and the band gap values are observed for all structures. While the random solid solution maintains the cubic structure after geometry optimization, all ordered solid solutions produce small distortions of the initial structure often to orthorhombic structure. The partially ordered solid solution where the $\mathrm{Zn}$ substitution in the $A$ and $B$ sites is ordered and random, respectively, gives a cubic final structure after the geometry optimization; however, it does not show a band gap, indicating that order of the $\mathrm{Zn}$ substitutions in the $\mathrm{Nb}$ sites is key to the observation of a gap.

For random solid solutions, only spin polarized calculations have resulted in a band gap, while all the other choices display no band gaps. For the selected BZN ordered solid solutions, only the primitive structure has given completed calculations for polarized spin. For nonspin polarized calculations, both symmetry and primitive structures produce band gaps and band structures with very small difference.

The absence of a band gap in the electronic structure of BZN random solid solutions strongly suggests that the real BZN structure is not randomly substituted, while some gaps can be encountered when ordered and partially ordered solid solutions in the $B$ site are investigated. The assumption of a random solid solution may be effective in structural determinations through the use of thermal ellipsoid factors, which average the exact atomic positions in the structure. However, DFT calculations indicate that to observe a band gap additional periodicities, not present in the random solid solution, may be required. Spin polarization may be introducing some additional periodicity in the random solid solution. Ordered and partially ordered solid solutions do introduce new periodicities and they could be present as domains with various orientations, so as to produce an overall cubic-like diffraction pattern. Therefore, the electronic band structures when some ordered solid solution is considered are, in general, more consistent with the optical absorption results. This observation includes the possible presence of impurity bands, which may also account for some of the optical and photocatalytic effects.

\section{Conclusions}

The photocatalytic properties of cubic BZN have been investigated for the first time. The BZN has been found to be UV light responsive; however, the photocatalytic activity of BZN is inferior to that of pure $\mathrm{BiNbO}_{4}$. Although the assumption of a random solid solution of $\mathrm{Zn}$ may give a reasonable explanation for the X-ray and neutron diffraction properties of cubic BZN structure, DFT calculations indicate that, to obtain band gaps in the electronic band structure, some degree of partial order in the substitution is required. This order results in band gaps that are more consistent with experimental optical absorption results and may be favored by enthalpy of formation arguments. Calculations also indicate the presence of impurity bands, which may be responsible for a small absorption edge in the mid-IR and for enhanced recombination and trapping of photogenerated electron-hole pairs compared to pure $\mathrm{BiNbO}_{4}$. Although the results indicate that substituted $\mathrm{Zn}$ does not produce enhancement of the photocatalytic properties, a methodology has been established which can be systematically used for the investigation of additional $3 d$-transition metal substitutions.

\section{Conflict of Interests}

The authors declare no conflict of interests regarding the publication of this paper.

\section{Acknowledgments}

The authors are thankful for Queensland University of Technology (QUT) for research facility support. Special thanks go to Mr. Mark Quinlan and Mr. Alexander Redman for their assistance with some experimental synthesis and the Material Studio Software, respectively.

\section{References}

[1] E. Gurr, Synthetic Dyes in Biology, Medicine and Chemistry, Elsevier, 2012.

[2] N. Martins, F. F. Vale, and H. Vieira, "Design and preliminary results of a DNA chip for the detection of microorganisms in water samples," Physica Status Solidi (C), vol. 7, no. 11-12, pp. 2751-2754, 2010.

[3] Z. Wang, M. Xue, K. Huang, and Z. Liu, "Textile dyeing wastewater treatment," in Advances in Treating Textile Effluent, chapter 5, InTech, 2011.

[4] I. M. Banat, P. Nigam, D. Singh, and R. Marchant, "Microbial decolorization of textile-dye-containing effluents: a review," Bioresource Technology, vol. 58, no. 3, pp. 217-227, 1996.

[5] U. I. Gaya and A. H. Abdullah, "Heterogeneous photocatalytic degradation of organic contaminants over titanium dioxide: a review of fundamentals, progress and problems," Journal of Photochemistry and Photobiology C: Photochemistry Reviews, vol. 9, no. 1, pp. 1-12, 2008.

[6] S. S. Dunkle and K. S. Suslick, "Photodegradation of binbo powder during photocatalytic reactions," Journal of Physical Chemistry C, vol. 113, no. 24, pp. 10341-10345, 2009.

[7] R. Shi, J. Lin, Y. Wang, J. Xu, and Y. Zhu, "Visible-light photocatalytic degradation of $\mathrm{BiTaO}_{4}$ photocatalyst and mechanism of photocorrosion suppression," Journal of Physical Chemistry C, vol. 114, no. 14, pp. 6472-6477, 2010.

[8] W. Yin, W. Wang, L. Zhou, S. Sun, and L. Zhang, "CTABassisted synthesis of monoclinic $\mathrm{BiVO}_{4}$ photocatalyst and its highly efficient degradation of organic dye under visible-light irradiation," Journal of Hazardous Materials, vol. 173, no. 1-3, pp. 194-199, 2010. 
[9] H. Fu, C. Pan, W. Yao, and Y. Zhu, "Visible-light-induced degradation of rhodamine $\mathrm{B}$ by nanosized $\mathrm{Bi}_{2} \mathrm{WO}_{6}$," The Journal of Physical Chemistry B, vol. 109, no. 47, pp. 22432-22439, 2005.

[10] X. Zhao, T. Xu, W. Yao, and Y. Zhu, "Photodegradation of dye pollutants catalyzed by $\gamma-\mathrm{Bi}_{2} \mathrm{MoO}_{6}$ nanoplate under visible light irradiation," Applied Surface Science, vol. 255, no. 18, pp. 80368040, 2009.

[11] H. An, Y. Du, T. Wang, C. Wang, W. Hao, and J. Zhang, "Photocatalytic properties of $\mathrm{BiOX}(\mathrm{X}=\mathrm{Cl}, \mathrm{Br}$, and I)," Rare Metals, vol. 27, no. 3, pp. 243-250, 2008.

[12] W. F. Yao, H. Wang, X. H. Xu et al., "Photocatalytic property of bismuth titanate $\mathrm{Bi}_{2} \mathrm{Ti}_{2} \mathrm{O}_{7}$," Applied Catalysis A: General, vol. 259, no. 1, pp. 29-33, 2004.

[13] Z. Zou, H. Arakawa, and J. Ye, "ubstitution effect of $\mathrm{Ta}^{5+}$ by $\mathrm{Nb}^{5+}$ on photocatalytic, photophysical, and structural properties of $\mathrm{BiTa}_{1-x} \mathrm{Nb}_{x} \mathrm{O}_{4}(0 \leqq x \leqq 1.0)$," Journal of Materials Research, vol. 17, no. 6, pp. 1446-1454, 2002.

[14] L. Zhang, Y. Man, and Y. Zhu, "Effects of Mo replacement on the structure and visible-light-induced photocatalytic performances of $\mathrm{Bi}_{2} \mathrm{WO}_{6}$ photocatalyst," ACS Catalysis, vol. 1, no. 8, pp. 841-848, 2011.

[15] L. L. Garza-Tovar, L. M. Torres-Martínez, D. B. Rodríguez, R. Gómez, and G. del Angel, "Photocatalytic degradation of methylene blue on $\mathrm{Bi}_{2} \mathrm{MNbO}_{7}(\mathrm{M}=\mathrm{Al}, \mathrm{Fe}, \mathrm{In}, \mathrm{Sm})$ sol-gel catalysts," Journal of Molecular Catalysis A: Chemical, vol. 247, no. 1-2, pp. 283-290, 2006.

[16] J. Ropero-Vega, K. L. Rosas-Barrera, J. A. Pedraza-Avella, D. A. Laverde-Cataño, J. E. Pedraza-Rosas, and M. E. Niño-Gómez, "Photophysical and photocatalytic properties of $\mathrm{Bi}_{2} \mathrm{MNbO}_{7}(\mathrm{M}$ $=\mathrm{Al}, \mathrm{In}, \mathrm{Ga}, \mathrm{Fe}$ ) thin films prepared by dip-coating," Materials Science and Engineering B, vol. 174, no. 1-3, pp. 196-199, 2010.

[17] L. M. Torres-Martinez, I. Juarez-Ramirez, J. S. Ramos-Garza, F. Vazquez-Acosta, and S. W. Lee, "Photocatalytic performance of pyrochlore-type structure compounds, $\mathrm{Bi}_{2} \mathrm{MTaO}_{7}(\mathrm{M}=\mathrm{Al}$, $\mathrm{Ga}, \mathrm{Fe}$ or $\mathrm{In}$ ), on alizarin red $\mathrm{S}$ degradation," in Proceedings of the 2nd WSEAS International Conference on Nanotechnology (NANOTECHNOLOGY '10), pp. 73-78, World Scientific and Engineering Academy and Society (WSEAS), Cambridge, UK, February 2010.

[18] L. M. Torres-Martinez, I. Juarez-Ramirez, J. S. Ramos-Garza, and F. Vazquez-Acosta, " $\mathrm{Bi}_{2} \mathrm{MTaO}_{7}(\mathrm{M}=\mathrm{Al}, \mathrm{Fe}, \mathrm{Ga}, \mathrm{In})$ photocatalyst for organic compounds degradation under UV and visible light," WSEAS Transactions on Environment and Development, vol. 6, pp. 286-295, 2010.

[19] L. Pontonnier, D. Fruchart, T. Fournier, and F. Vaillant, "Relationships between structural and electric properties of pure and mixed protonic conductors," Solid State Ionics, vol. 37, no. 4, pp. 307-316, 1990.

[20] M. P. Van Dijk, A. J. Burggraaf, A. N. Cormack, and C. R. A. Catlow, "Defect structures and migration mechanisms in oxide pyrochlores," Solid State Ionics, vol. 17, no. 2, pp. 159-167, 1985.

[21] B. Shen, L. Kang, and X. Yao, "Dielectric properties of $\mathrm{Bi}_{2} \mathrm{O}_{3}$ $\mathrm{ZnO}-\mathrm{Ta}_{2} \mathrm{O}_{5}$ ceramics sintered by microwave," Journal of Electroceramics, vol. 21, no. 1-4, pp. 448-451, 2008.

[22] T. S. Kayed and A. Mergen, "Electrical properties of $\mathrm{Bi}_{1.5} \mathrm{ZnSb}_{1.5} \mathrm{O}_{7}$ pyrochlore ceramics," Crystal Research and Technology, vol. 38, no. 12, pp. 1077-1081, 2003.

[23] V. Sirotinkin and A. Bush, "Preparation and dielectric properties of $\mathrm{Bi}_{1.5} \mathrm{MNb}_{1.5} \mathrm{O}_{7}(\mathrm{M}=\mathrm{Cu}, \mathrm{Mg}, \mathrm{Mn}, \mathrm{Ni}, \mathrm{Zn})$ pyrochlore oxides," Inorganic Materials, vol. 39, no. 9, pp. 974-977, 2003.
[24] S. Jiang, Y. Li, R. Li et al., "Dielectric properties and tunability of cubic pyrochlore $\mathrm{Bi}_{1.5} \mathrm{MgNb}_{1.5} \mathrm{O}_{7}$ thin films," Applied Physics Letters, vol. 94, no. 16, Article ID 162908, 3 pages, 2009.

[25] M. Valant and P. K. Davies, "Synthesis and dieletric properties of pyrochlore solid solutions in the $\mathrm{Bi}_{2} \mathrm{O}_{3}-\mathrm{ZnO}-\mathrm{Nb}_{2} \mathrm{O}_{5}-\mathrm{TiO}_{2}$ system," Journal of Materials Science, vol. 34, no. 22, pp. 5437$5442,1999$.

[26] A. F. Qasrawi, B. H. Kmail, and A. Mergen, "Synthesis and characterization of $\mathrm{Bi}_{1.5} \mathrm{Zn}_{0.92} \mathrm{Nb}_{1.5-x} \mathrm{Sn}_{x} \mathrm{O}_{6.92-x / 2}$ pyrochlore ceramics," Ceramics International, vol. 38, no. 5, pp. 4181-4187, 2012.

[27] A. F. Qasrawi and A. Mergen, "Structural, electrical and dielectric properties of $\mathrm{Bi}_{1.5} \mathrm{Zn}_{0.92} \mathrm{Nb}_{1.5-x} \mathrm{Ta}_{x} \mathrm{O}_{6.92}$ pyrochlore ceramics," Ceramics International, vol. 38 , no. 1 , pp. 581-587, 2012.

[28] A. Mergen, H. Zorlu, M. Özdemir, and M. Yumak, "Fabrication and characterisation of $\mathrm{Cr}$ and $\mathrm{Co}$ doped $\mathrm{Bi}_{1.5} \mathrm{Zn}_{0.92} \mathrm{Nb}_{1.5} \mathrm{O}_{6.92}$ pyrochlores," Journal of the European Ceramic Society, vol. 31, no. 14, pp. 2633-2639, 2011.

[29] A. Mergen, H. Zorlu, M. Özdemir, and M. Yumak, "Dielectric properties of $\mathrm{Sm}, \mathrm{Nd}$ and $\mathrm{Fe}$ doped $\mathrm{Bi}_{1.5} \mathrm{Zn}_{0.92} \mathrm{Nb}_{1.5} \mathrm{O}_{6.92}$ pyrochlores," Ceramics International, vol. 37, no. 1, pp. 37-42, 2011.

[30] H. Du, X. Yao, and H. Wang, "Dielectric properties of pyrochlore $\left(\mathrm{Bi}_{1.5} \mathrm{Zn}_{0.5}\right)\left(\mathrm{Nb}_{0.5} M_{1.5} \mathrm{O}_{7}(M=\mathrm{Ti}, \mathrm{Sn}, \mathrm{Zr}\right.$, and Ce $)$ dielectrics," Applied Physics Letters, vol. 88, no. 21, Article ID 212901, 2006.

[31] D. P. Cann, C. A. Randall, and T. R. Shrout, "Investigation of the dielectric properties of bismuth pyrochlores," Solid State Communications, vol. 100, no. 7, pp. 529-534, 1996.

[32] I. Levin, T. G. Amos, J. C. Nino, T. A. Vanderah, C. A. Randall, and M. T. Lanagan, "Structural study of an unusual cubic pyrochlore $\mathrm{Bi}_{1.5} \mathrm{Zn}_{0.92} \mathrm{Nb}_{1.5} \mathrm{O}_{6.92}$," Journal of Solid State Chemistry, vol. 168, no. 1, pp. 69-75, 2002.

[33] W. Hong, D. Huiling, and Y. Xi, "Structural study of $\mathrm{Bi}_{2} \mathrm{O}_{3}$ $\mathrm{ZnO}-\mathrm{Nb}_{2} \mathrm{O}_{5}$ based pyrochlores," Materials Science and Engineering B: Solid-State Materials for Advanced Technology, vol. 99, no. 1-3, pp. 20-24, 2003.

[34] R. L. Withers, T. R. Welberry, A.-K. Larsson et al., "Local crystal chemistry, induced strain and short range order in the cubic pyrochlore $\quad\left(\mathrm{Bi}_{1.5-\alpha} \mathrm{Zn}_{0.5-\beta}\right)\left(\mathrm{Zn}_{0.5-\gamma} \mathrm{Nb}_{1.5-\delta}\right) \mathrm{O}_{(7-1.5 \alpha-\beta-\gamma-2.5 \delta)}$ (BZN)," Journal of Solid State Chemistry, vol. 177, no. 1, pp. 231-244, 2004.

[35] S. Kamba, V. Porokhonskyy, A. Pashkin et al., "Anomalous broad dielectric relaxation in $\mathrm{Bi}_{1.5} \mathrm{ZnNb}_{1.5} \mathrm{O}_{7}$ pyrochlore," Physical Review B, vol. 66, no. 5, Article ID 054106, 2002.

[36] G. Perenlei, P. C. Talbot, and W. N. Martens, "Sol-gel synthesis and characterization of cubic bismuth zinc niobium oxide nanopowders," Journal of Nanomaterials, vol. 2014, Article ID 695973, 6 pages, 2014.

[37] B. B. Hinojosa, Atomic Structure Effects on Bulk and Surface Properties of Mixed Metal Oxides from First Principles Simulations, University of Florida, 2010. 

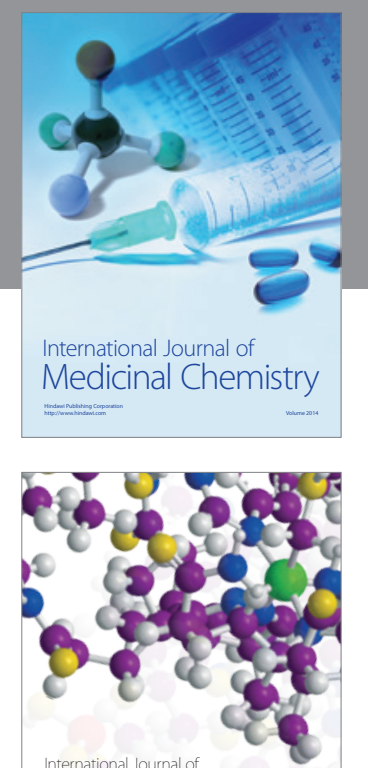

\section{Carbohydrate} Chemistry

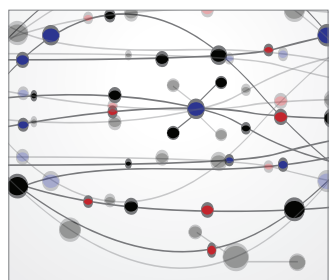

The Scientific World Journal
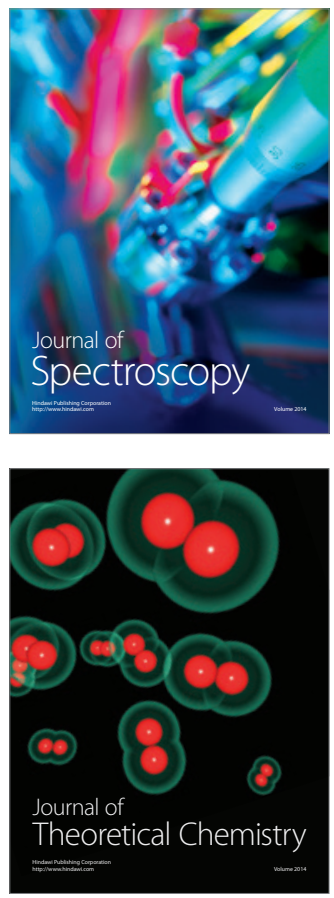
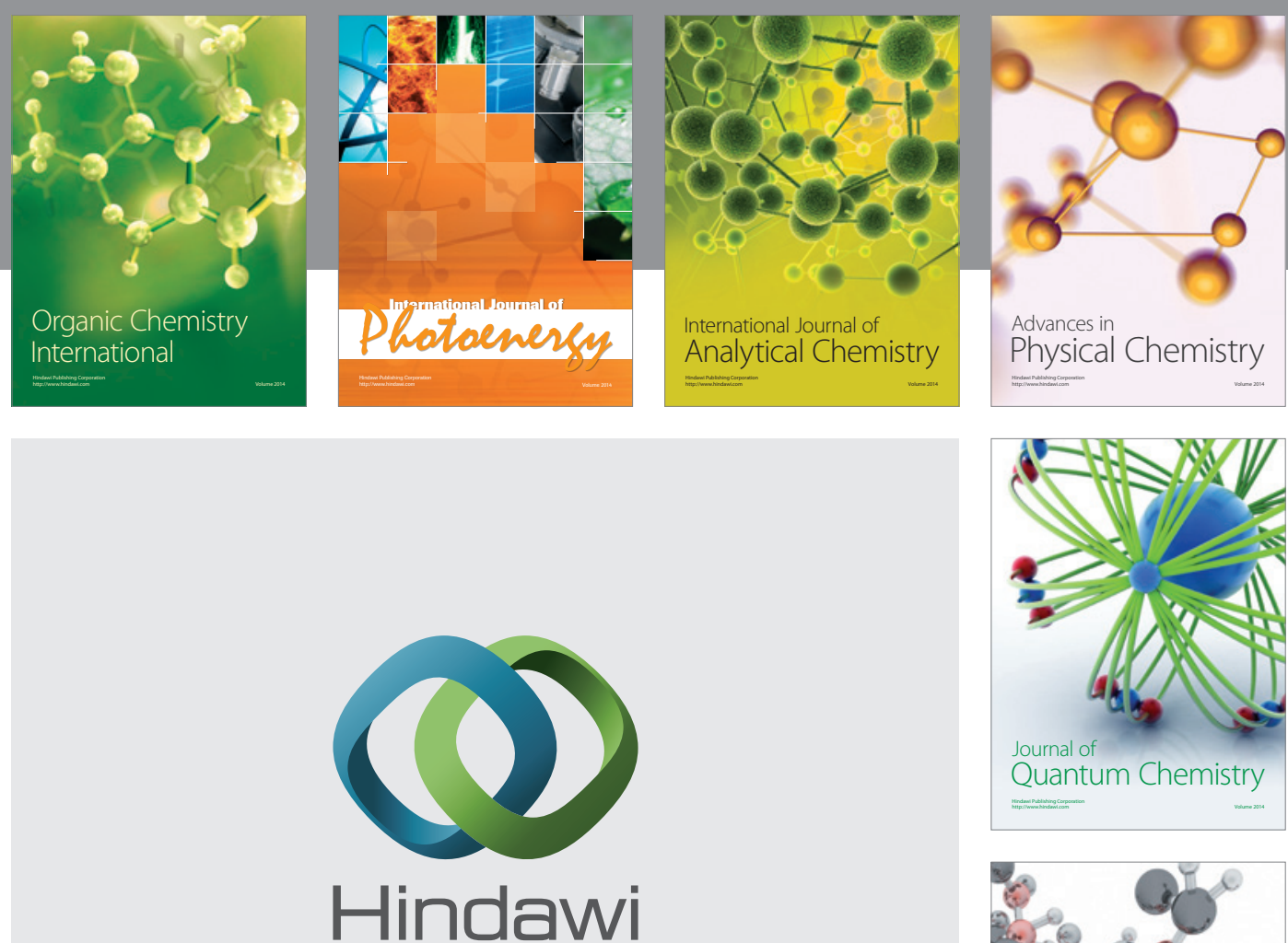

Submit your manuscripts at

http://www.hindawi.com

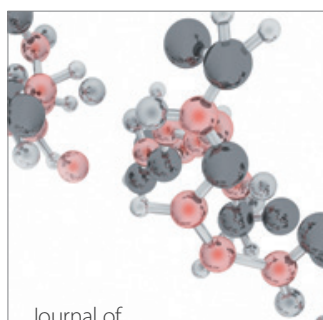

Analytical Methods

in Chemistry

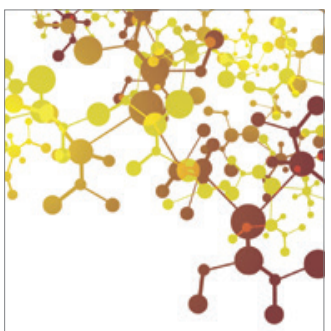

Journal of

Applied Chemistry

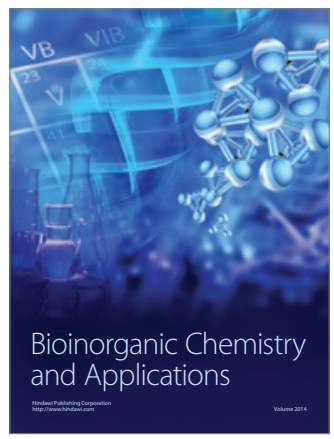

Inorganic Chemistry
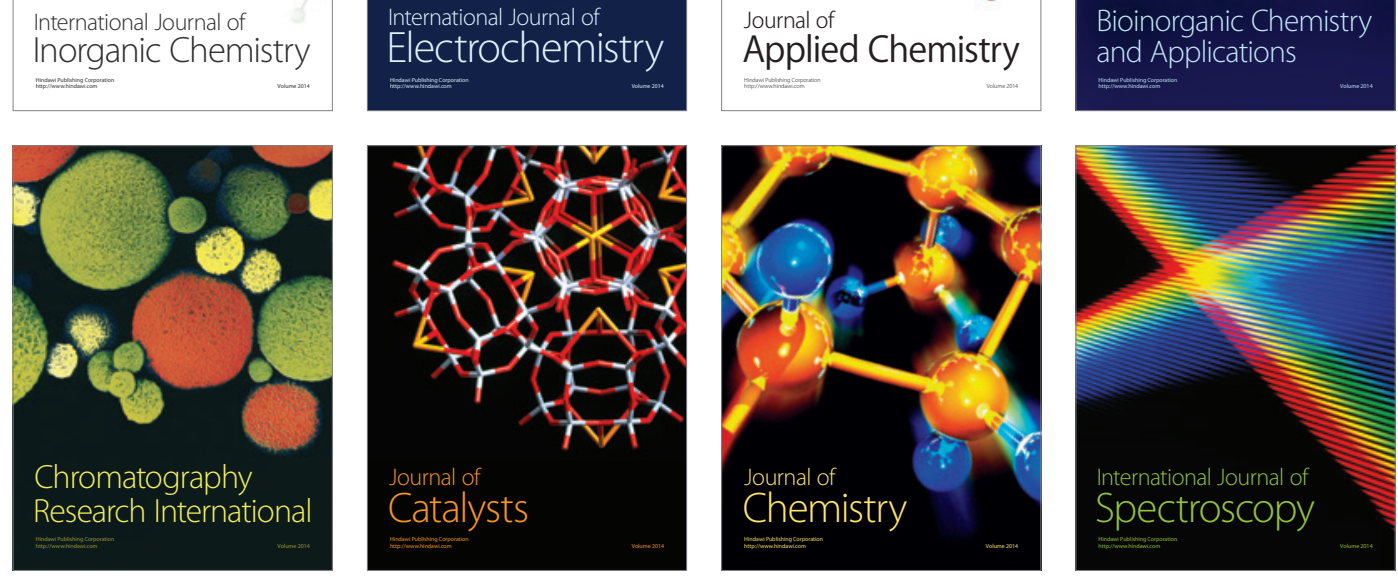